\title{
Efeito da proporção canjiquinha:soja na solubilidade, dispersibilidade e propriedades emulsificantes de mingaus desidratados ${ }^{(1)}$
}

\begin{abstract}
Sin-Huei Wang ${ }^{(2)}$, Geraldo Gonçalves Borges ${ }^{(2)}$, Lair Chaves Cabral(3) e Flávia Batista Araujo ${ }^{(2)}$
Resumo - Com o objetivo de verificar a possibilidade do uso dos mingaus desidratados elaborados com canjiquinha e soja em diferentes proporções (100:0; 90:10; 80:20; 70:30; 60:40 e 50:50\%), em produtos alimentícios, foram estudadas a solubilidade e as propriedades emulsificantes das misturas. Os processos utilizados para a obtenção dos mingaus foram: decorticagem dos grãos de soja, branqueamento, desintegração e homogeneização da canjiquinha e soja, bem como secagem por atomização. $\mathrm{O}$ aumento das proporções de soja $(0$ a $50 \%)$ causou aumento do $\mathrm{N}$ solúvel em água, do índice de solubilidade de $\mathrm{N}$, da proteína dispersível em água, do índice de dispersibilidade de proteína, e provocou uma ligeira diminuição da atividade emulsificante e da estabilidade de emulsão. A atividade residual do inibidor de tripsina não foi detectada nos mingaus desidratados estudados.
\end{abstract}

Termos para indexação: milho, mistura, proteínas, propriedades físico-químicas.

\section{Effect of corn grits:soybean ration on solubility, dispersibility and emulsifying properties of dehydrated porridges}

\begin{abstract}
Dehydrated corn grits-soybean porridges at different proportions (100:0; 90:10; 80:20; 70:30; 60:40 e 50:50\%) were assessed for nitrogen solubility index (NSI), protein dispersibility index (PDI), emulsifying activity (EA) and emulsion stability (ES) in order to verify their potential use as food ingredients. Dehydrated porridge was manufactured by soybean seed dehulling, blanching, disintegration of bleached corn grits and soybean, homogenization and spray drying. The results indicated that increasing soybean proportion from 0 to $50 \%$ caused an increase in the soluble nitrogen in water, NSI, dispersible protein in water and PDI, and a slight decrease in the EA and ES. No trypsin inhibitor activity was detected in studied dehydrated porridges.
\end{abstract}

Index terms: maize, mixing, proteins, chemicophysical properties.

\section{Introdução}

Alguns estudos (Bressani et al., 1981; Zoia et al., 1997) demonstraram os efeitos benéficos da combinação de milho e soja desde longo tempo. A mistura em proporções adequadas de milho e soja apresenta um efeito complementar mútuo de aminoácidos. No entanto, a aceitação de um ingrediente protéico

\footnotetext{
(1) Aceito para publicação em 24 de abril de 2000.

(2) Universidade Federal Rural do Rio de Janeiro, Dep. Economia Doméstica, BR 465, km 47, CEP 23851-970 Seropédica, RJ E-mail: sin-hueiwang@bol.com.br

${ }^{(3)}$ Embrapa-Centro Nacional de Pesquisa de Tecnologia Agroindustrial de Alimentos, Av. das Américas, 29501 CEP 23020-470 Guaratiba, RJ. E-mail: lcc@ctaa.embrapa.br
}

pela indústria de alimentos não está condicionada apenas às suas qualidades nutricionais, mas também, entre outros fatores, às suas propriedades funcionais que desempenham papéis decisivos. Solubilidade e propriedades emulsificantes são propriedades funcionais importantes nas formulações de alimentos como produtos cárneos, maionese, molhos, sopas e outros (Visser \& Thomas, 1987).

Solubilidade ou dispersibilidade das proteínas da soja é uma propriedade físico-química relacionada com as outras propriedades funcionais, razão pela qual é a primeira propriedade a ser estudada numa investigação sistemática (Mattil, 1971;Hermansson, 1979).

A capacidade que as proteínas da soja possuem para melhorar certas propriedades num sistema alimentar, tais como a formação e a estabilidade de emulsão, depende de numerosos fatores. Conteúdo 
de proteína, solubilidade, dispersibilidade, $\mathrm{pH}$ do meio, temperatura e métodos de processamento, afetam as propriedades funcionais das proteínas da soja (Crenwelge et al., 1974; Hutton \& Campbell, 1977).

Este trabalho teve como objetivo avaliar a solubilidade, a dispersibilidade e as propriedades emulsificantes de mingaus desidratados elaborados com diferentes proporções de canjiquinha:soja visando utilizá-los na melhoria de características tecnológicas de produtos alimentícios.

\section{Material e Métodos}

Foram usados canjiquinha e grãos de soja (Glycine $\max ($ L.) Merrill, cultivar BR-16, safra de 1996), ambos adquiridos do comércio e da Embrapa-Serviço de Produção de Sementes Básicas (Ponta Grossa, PR), respectivamente.

A obtenção do mingau desidratado, as análises químicas e a atividade do inibidor de tripsina que se seguem foram feitas em triplicata.

Nas matérias-primas e nos produtos desidratados, realizaram-se as seguintes determinações: umidade, extrato etéreo, proteína bruta e cinzas, segundo American Association of Cereal Chemists (1969), e fibra bruta, conforme Kamer \& Ginkel (1952).

Os grãos de soja foram decorticados, usando-se um descascador mecânico de grãos. Os grãos decorticados e a canjiquinha foram branqueados separadamente, com água em ebulição, na proporção de matéria-prima:água de 1:5 e 1:8, durante 20 e $10 \mathrm{~min}$, respectivamente. Em seguida, a água de branqueamento da soja foi drenada, porém utilizada a da canjiquinha. A canjiquinha e os grãos de soja decorticados, ambos branqueados, foram misturados nas respectivas proporções de 100:0; 90:10; 80:20; 70:30; 60:40 e 50:50\% (base seca), correspondendo, respectivamente, ao controle e às formulações I, II, III, IV e V, sendo desintegrados com água em ebulição, num moinho de facas e martelos, marca Treu S.A. ( $\mathrm{N}^{\circ}$ 63.202), com peneira de $0,5 \mathrm{~mm}$, obtendo-se uma mistura com aproximadamente 6-8\% de sólidos. Esta mistura foi homogeneizada em homogeneizador APV Gaulin, modelo $15 \mathrm{MR}$, a $70^{\circ} \mathrm{C}$ e 5.000 psi, e obteve-se, então, o mingau líquido. $\mathrm{O}$ controle e as cinco fórmulas de mingau líquido assim obtidos foram secados por atomização em atomizador centrífugo Spray Dryer Niro Atomizer 8.114, com temperatura de entrada e saída de $200^{\circ} \mathrm{C}$ e $90^{\circ} \mathrm{C}$, respectivamente, tendo como produtos finais mingaus desidratados: con- trole e formulações I, II, III, IV e V.

A atividade do inibidor de tripsina foi determinada segundo o método original de Kunitz, conforme descrito por Kakade et al. (1969), consistindo na digestão da caseína pela enzima tripsina, onde se determinou sua atividade, pela introdução do inibidor dos mingaus, submetidos ou não à fervura.

Considerando-se a definição de unidade de tripsina (UT) como sendo o aumento de 0,01 unidade de absorbância a $280 \mathrm{~nm}$ nas condições do teste, calcularamse as unidades de tripsina inibida (UTI) pela diferença entre as unidades de tripsina totais (UT) da atividade máxima, e as da amostra contendo o inibidor.

O índice de solubilidade de $\mathrm{N}$ (ISN) foi determinado segundo o método descrito na American Association of Cereal Chemists (1969), destacando-se pela técnica de lenta agitação. O ISN foi calculado pela relação: $\%$ ISN $=(\%$ nitrogênio solúvel em água/\% nitrogênio total) x 100 .

O índice de dispersibilidade de proteína (IDP) foi determinado conforme o método da American Oil Chemists' Society (1980), destacando-se pela técnica de rápida agitação. O IDP foi calculado pela relação: $\% \mathrm{IDP}=(\%$ proteína dispersível em água/\% proteína total) $\mathrm{x} 100$.

As propriedades emulsificantes abrangem a atividade emulsificante (AE) e a estabilidade de emulsão (EE), ambas determinadas segundo o método de Dench et al. (1981). Para o cálculo da AE e da EE, foram utilizadas as respectivas relações:

$\% \mathrm{AE}=$ (altura da camada emulsificada/altura total do fluido) x 100.

$\% \mathrm{EE}=$ (altura da camada emulsificada após aquecimento/altura total do fluido) $\mathrm{x} 100$.

Quanto aos resultados da composição centesimal aproximada, do ISN, do IDP e das propriedades emulsificantes, foram feitas análises estatísticas quantitativas, por meio de equações de regressão a $95 \%$ de confiabilidade, com base nos coeficientes de determinação $\left(\mathrm{R}^{2}\right)$ apresentados. Foram determinados os coeficientes de correlação entre os parâmetros relacionados.

Todas as análises estatísticas foram realizadas segundo os métodos descritos por Pimentel-Gomes (1982).

\section{Resultados e Discussão}

A soja mostrou teores de proteína, extrato etéreo, cinzas e fibra bruta superiores aos da canjiquinha, enquanto na canjiquinha o maior conteúdo foi de carboidrato (Tabela 1). A soja decorticada apresen- 
tou teores de proteína e extrato etéreo maiores do que os da soja integral, o que indica que a casca de soja contém maiores teores de cinzas e fibra bruta.

As composições químicas dos diferentes mingaus desidratados e as relações entre a porcentagem de soja e as porcentagens de suas proteínas, extrato etéreo, cinzas, fibra bruta e carboidrato são apresentados, respectivamente, nas Tabelas 2 e 3 .

Os teores de proteína, extrato etéreo, cinzas e fibra bruta aumentaram com o aumento das proporções de soja (0 a 50\%) nos mingaus desidratados, e o aumento foi mais acentuado nos teores de proteína. A adição de 10; 20; 30; 40 e 50\% de soja aumentou teores de proteína (\% base seca) de 8,66 para 12,22 ; 16,$53 ; 19,94 ; 25,53$ e $27,23 \%$, respectivamente $(\mathrm{Ta}-$

Tabela 1. Composição centesimal aproximada (\% base seca) da canjiquinha e dos grãos de soja integral e decorticada.

\begin{tabular}{lccc}
\hline Composição & Canjiquinha & Soja integral & $\begin{array}{c}\text { Soja } \\
\text { decorticada }\end{array}$ \\
\hline Proteína & 8,74 & 40,03 & 42,41 \\
Extrato etéreo & 0,88 & 22,93 & 25,03 \\
Cinzas & 0,43 & 5,24 & 4,80 \\
Fibra bruta & 1,05 & 5,85 & 1,83 \\
Carboidratos $^{(1)}$ & 88,90 & 25,95 & 25,93 \\
\hline
\end{tabular}

${ }^{(1)}$ Calculado por diferença $[100$ - (proteína + extrato etéreo + cinzas + fibra bruta)] bela 2). Resultados semelhantes foram encontrados por Nyotu et al. (1986).

Não foi detectada atividade residual do inibidor de tripsina nos mingaus desidratados estudados, o que indica que o branqueamento de soja na água fervente por $20 \mathrm{~min}$ antes de sua desintegração foi o suficiente para inativar completamente o inibidor de tripsina. Resultado semelhante foi verificado por Soetrisno et al. (1982).

Os resultados do N solúvel em água (NSA), do índice de solubilidade do N (ISN), da proteína dispersível em água (PDA), do índice de dispersibilidade de proteína (IDP), da atividade emulsificante (AE) e da estabilidade de emulsão (EE), e as relações entre essas variáveis e a porcentagem de soja nos mingaus desidratados são apresentados, respectivamente, nas Tabelas 4 e 5 .

Visser \& Thomas (1987) relataram que o ISN e o IDP são usados para determinar a solubilidade de proteínas de alimentos. Estes dois índices são indicações grosseiras do grau de desnaturação da proteína, sofrida ao longo do processamento. Quanto maior for a solubilidade, menor será o grau de desnaturação, embora a solubilidade e a desnaturação nem sempre se correlacionem entre si. Valores altos de solubilidade são, às vezes, obtidos a partir de proteínas completamente desnaturadas.

Tabela 2. Composição centesimal aproximada (base seca) dos mingaus desidratados elaborados com canjiquinha e soja em diferentes proporções.

\begin{tabular}{ccccccc}
\hline Formulação & $\begin{array}{c}\text { Proporção } \\
\text { canjiquinha:soja }\end{array}$ & $\begin{array}{c}\text { Proteína } \\
-\end{array}$ & Extrato etéreo & Cinzas & Fibra bruta & Carboidratos $^{(1)}$ \\
\hline Controle & $100: 00$ & 8,66 & 0,29 & 0,44 & 1,75 & 88,86 \\
I & $90: 10$ & 12,22 & 1,87 & 0,84 & 2,51 & 82,56 \\
II & $80: 20$ & 16,53 & 3,16 & 1,21 & 2,58 & 76,52 \\
III & $70: 30$ & 19,94 & 4,56 & 1,44 & 2,65 & 71,41 \\
IV & $60: 40$ & 25,53 & 6,23 & 1,88 & 2,70 & 63,66 \\
V & $50: 50$ & 27,23 & 7,37 & 2,11 & 2,68 & 60,61 \\
\hline
\end{tabular}

${ }^{(1)}$ Calculado pela diferença $[100$ - (proteína + extrato etéreo + cinzas + fibra bruta)].

Tabela 3. Equações de regressão e coeficiente de determinação $\left(\mathrm{R}^{2}\right)$ entre as porcentagens de proteínas, extrato etéreo, cinzas, fibra bruta, carboidrato e a porcentagem de soja dos mingaus desidratados elaborados com canjiquinha e soja em diferentes proporções.

\begin{tabular}{lc}
\hline Equação de regressão & $\mathrm{R}^{2}$ \\
\hline Proteína $(\%)=8,62+0,39(\%$ soja $)$ & 0,9899 \\
Extrato etéreo $(\%)=0,35+0,14(\%$ soja $)$ & 0,9983 \\
Cinzas $(\%)=0,48+0,03(\%$ soja $)$ & 0,9931 \\
Fibra bruta $(\%)=1,86+0,05\left(\%\right.$ soja) $-0,007(\% \text { soja })^{2}$ & 0,8915 \\
Carboidrato $(\%)=88,44-0,58(\%$ soja $)$ & 0,9929 \\
\hline
\end{tabular}


Borderías \& Montero (1988) constataram que a solubilidade da proteína depende diretamente da proporção de grupos hidrofóbicos e hidrofílicos, localizados no centro e na superfície da molécula, respectivamente.

O NSA, o ISN, a PDA e o IDP aumentaram linearmente com o aumento das proporções de soja ( 0 a $50 \%$ ) nos mingaus desidratados (Tabelas 4 e 5). O NSA teve correlação positiva com o ISN $(r=0,9973)$, significativo a $5 \%$ de probabilidade, indicando, assim, que o NSA aumentou com o aumento do ISN. Portanto, sugere-se que o aumento do NSA encontrado nos mingaus desidratados pode ter sido atribuído ao aumento dos teores de proteína $(8,66$ a $27,23 \%$ ), em razão do aumento das proporções de soja (Tabela 2), uma vez que a proteína de soja é mais hidrofílica, solúvel em água ou soluções salinas diluídas em $\mathrm{pH}$ acima ou abaixo do seu ponto isoelétrico, conforme Wolf (1970). O mesmo comportamento foi observado entre a PDA e o IDP $(r=0,9876)$, significativo a $5 \%$ de probabilidade.

Segundo McWatters \& Holmes (1979), o nível da solubilidade do $\mathrm{N}$ da farinha de soja diminui pela aplicação de calor úmido, e a maior redução da solubilidade ocorre durante os primeiros $10 \mathrm{~min}$ de aque- cimento. Desta forma, era de se esperar que, no presente trabalho, o branqueamento da soja diminuísse a sua solubilidade. Porém, isso não ocorreu, pois o aumento das proporções de soja aumentou o NSA, o ISN, a PDA e o IDP, o que pode ser explicado pelo efeito de homogeneização aplicada durante o preparo de mingau desidratado. A homogeneização, de acordo com Cheftel et al. (1989), pode provocar uma fragmentação dos agregados protéicos em partículas pequenas, melhorando a sua solubilidade.

Phillips \& Sternberg (1979) constataram que as proteínas (prolaminas e glutelinas) de milho apresentam baixa solubilidade, nas condições em que se encontram nos alimentos. Desta forma, explica-se também o aumento de NSA, ISN, PDA e IDP com a diminuição das proporções de canjiquinha nos mingaus desidratados estudados no presente trabalho.

Houve correlação positiva entre NSA x PDA $(\mathrm{r}=0,9916)$ e ISN x IDP $(\mathrm{r}=0,9756)$, nos mingaus desidratados, e ambos coeficientes foram significativos a 5\% de probabilidade. Entretanto, acredita-se que, nem sempre a PDA contribui para a NSA, ou seja, uma proteína pode ser dispersível em água, mas ela não é obrigatoriamente solúvel em água. Porém, o IDP e o ISN são intimamente relacionados, o que

Tabela 4. Nitrogênio solúvel em água (NSA), índice de solubilidade de nitrogênio (ISN), proteína dispersível em água (PDA), índice de dispersibilidade de proteína (IDP), atividade emulsificante (AE) e estabilidade de emulsão (EE) dos mingaus desidratados elaborados com canjiquinha e soja em diferentes proporções.

\begin{tabular}{cccccccc}
\hline Formulação & $\begin{array}{c}\text { Proporção } \\
\text { canjiquinha:soja }\end{array}$ & $\begin{array}{c}\text { NSA } \\
(\% \text { b.s. })\end{array}$ & $\begin{array}{c}\text { ISN } \\
(\%)\end{array}$ & $\begin{array}{c}\text { PDA } \\
(\% \text { b.s. })\end{array}$ & $\begin{array}{c}\text { IDP } \\
(\%)\end{array}$ & $\begin{array}{c}\text { AE } \\
(\% \text { b.s. })\end{array}$ & $\begin{array}{c}\text { EE } \\
(\% \text { b.s. })\end{array}$ \\
\hline Controle & $100: 00$ & 0,11 & 7,87 & 0,84 & 9,77 & 81,93 & 81,93 \\
I & $90: 10$ & 0,18 & 9,39 & 1,93 & 15,85 & 81,84 & 81,84 \\
II & $80: 20$ & 0,29 & 10,82 & 3,53 & 21,37 & 81,14 & 81,14 \\
III & $70: 30$ & 0,44 & 13,64 & 5,73 & 28,71 & 80,33 & 80,33 \\
IV & $60: 40$ & 0,72 & 17,52 & 8,14 & 32,90 & 79,71 & 79,71 \\
V & $50: 50$ & 0,86 & 19,63 & 11,02 & 40,86 & 78,13 & 78,13 \\
\hline
\end{tabular}

Tabela 5. Equações de regressão e coeficientes de determinação $\left(\mathrm{R}^{2}\right)$ entre as porcentagens dos parâmetros de propriedades funcionais e a porcentagem de soja dos mingaus desidratados elaborados com canjiquinha e soja em diferentes proporções.

\begin{tabular}{lc}
\hline Equação de regressão & $\mathrm{R}^{2}$ \\
\hline Nitrogênio solúvel em água (\% b.s.) $=0,04+0,02(\%$ soja $)$ & 0,9587 \\
Índice de solubilidade de nitrogênio $(\%)=7,00+0,25(\%$ soja $)$ & 0,9717 \\
Proteína dispersível em água $(\%$ b.s. $)=0,07+0,20(\%$ soja $)$ & 0,9762 \\
Índice de dispersibilidade de proteína $(\%)=9,70+0,61(\%$ soja $)$ & 0,9966 \\
Atividade emulsificante $(\%$ b.s. $)=82,38-0,07(\%$ soja) & 0,9386 \\
Estabilidade de emulsão $(\%$ b.s. $)=82,38-0,07(\%$ soja) & 0,9324 \\
\hline
\end{tabular}


foi demonstrado por Volkert \& Klein (1979) num estudo de IDP e por Hutton \& Campbell (1977) num estudo de ISN em diferentes produtos de soja (isolado, concentrado e flocos). Os resultados obtidos no presente trabalho com IDP mostraram comportamentos semelhantes aos encontrados com ISN.

De acordo com Visser \& Thomas (1987), o ISN e o IDP são sempre usados como guias práticos para conhecer a funcionalidade da proteína. Sem dúvida, valores altos de ISN e IDP são bastante úteis para formar uma emulsão real em produtos cárneos. No entanto, os produtos com baixos valores de ISN e IDP podem ser ainda funcionais, pois apresentam boa absorção de água e de gordura, as quais mostram efeito consideravelmente positivo na estabilidade do sistema cárneo.

Quanto maior foi a proporção de soja nos mingaus desidratados, menores foram os valores da atividade emulsificante (AE) e da estabilidade da emulsão (EE) (Tabelas 4 e 5) a equação linear foi a que mais se ajustou aos dados obtidos (Tabela 5).

De acordo com vários autores (Yasumatsu et al., 1972; Dench et al., 1981; Nath \& Rao, 1981), as propriedades emulsificantes (AE e EE) da proteína de soja têm sido intimamente relacionadas com o seu conteúdo de proteína ou $\mathrm{N}$ solúvel. Conforme Borderías \& Montero (1988) e Cheftel et al. (1989), a solubilidade das proteínas em água contribui para a diminuição da tensão interfacial entre os componentes hidrofóbicos e hidrofílicos, e aumenta as propriedades emulsificantes. Esta redução na tensão interfacial causada pelas proteínas pode evitar, segundo Hidalgo (1977), a sedimentação de proteínas de baixa solubilidade.

Estes fatos são contrários aos resultados obtidos no presente trabalho, no qual foi verificada uma correlação negativa entre as propriedades emulsificantes (AE e EE) e solubilidade de proteína (NSA, ISN, PDA e IDP), apresentando coeficientes de correlação (r) iguais a $-0,7881,-0,7770,-0,8285,-0,8174$, $-0,7901,-0,7789,-0,8307$ e - 0,8183 , para AE x NSA, AE x ISN, AE x PDA, AE x IDP, EE x NSA, EE x ISN, EE x PDA e EE x IDP, respectivamente, e significativos a 5\% de probabilidade. Em contraposição, $\mathrm{AE}$ e EE foram positivamente correlacionadas entre si $(r=0,9995)$, significativo a $5 \%$ de probabilidade.

Acredita-se que o aumento dos teores de fibra bruta ( 1,75 a 2,68\%), bem como os dos lipídios $(0,29$ a 7,37\%) com o aumento das proporções de soja (Tabela 2), tenha diminuído as propriedades emulsificantes (AE e EE), uma vez que, as propriedades emulsificantes correlacionam negativamente com o conteúdo de fibra bruta (Yasumatsu et al., 1972), e que o alto conteúdo de gordura de floco de soja pode reduzir a sua habilidade como agente emulsificante (Volkert \& Klein, 1979).

Por outro lado, Visser \& Thomas (1987) relataram que a proteína de soja encapsula as gotículas de gordura e forma uma rede contínua de proteína-gel através da fase aquosa, desempenhando, desta forma, sua função emulsificante.

Não houve diferença significativa entre EE e AE, pois a equação de regressão da $\mathrm{EE}$ foi igual à da $\mathrm{AE}$ (Tabela 5). Acredita-se que no presente trabalho o branqueamento aplicado na canjiquinha e soja tenha aumentado a hidrofobicidade na superfície das proteínas, de modo que, tanto a AE como a EE tenham atingido os seus máximos valores. Matsudomi et al., (1985) atribuíram os aumentos de AE e EE, obtidos após o tratamento térmico a $95^{\circ} \mathrm{C}$ por $30 \mathrm{~min}$, ao aumento de hidrofobicidade na superfície das proteínas.

\section{Conclusões}

1. Com o aumento das proporções de soja ( 0 a $50 \%$ ) nos mingaus desidratados de canjiquinha e soja ocorre um aumento no $\mathrm{N}$ solúvel em água, no índice de solubilidade de $\mathrm{N}$, na proteína dispersível em água e no índice de dispersibilidade de proteína, porém uma diminuição na atividade emulsificante e na estabilidade de emulsão.

2. Os mingaus desidratados elaborados respectivamente com 80:20; 70:30; 60:40 e 50:50\% de canjiquinha:soja podem ser sugeridos como ingredientes na formulação de produtos cárneos, extensores de carne, queijos processados, maionese, sopas, molhos, produtos de confeitaria e de chocolateria.

\section{Referências}

AMERICAN ASSOCIATION OF CEREAL CHEMISTS (St. Paul, Estados Unidos). Approved methods of the American Association of Cereal Chemists. 7. ed. St. Paul, 1969. 2v.

AMERICAN OIL CHEMISTS' SOCIETY (Champaign, Estados Unidos). Official and tentative methods of the American Oil Chemists Society. 3. ed. Champaign, 1980.

BORDERÍAS, A. J.; MONTERO, P. Fundamentos de la funcionalidad de las proteínas en alimentos. Revista Agroquímica y Tecnología de Alimentos, Valencia, v. 28, n. 2, p. 159-169, jun./ago. 1988. 
BRESSANI, R.; HERNANDEZ, E.; CÓLON, A.; WOLZAK, A.; GÓMEZ-BRENES, R. Efecto suplementario de tres fuentes de proteína de soya sobre diferentes selecciones o productos de maíz.Archivos Latinoamericanos de Nutrición, Caracas, v. 31, n. 1, p. 52-62, mar. 1981.

CHEFTEL, J. C.; CUQ, J. L.; LORIENT, D. Proteínas alimentarías. Zaragoza : Acribia, 1989. 346 p.

CRENWELGE, D. D.; DILL, C. W.; TYBOR, P. T.; LANDMANN, W. A. A comparison of the emulsification capacities of some protein concentrates. Journal of Food Science, Chicago, v. 39, n. 1, p. 175-177, Jan./Feb. 1974.

DENCH, J. E.; RIVAS, R. N.; CAYGILL, J. C. Selected functional properties of sesame (Sesamum indicum L.) flour and two protein isolates. Journal of the Science of Food and Agriculture, Chichester, v. 32, n. 6, p. 557-564, June 1981.

HERMANSSON, A. M. Methods of studying functional characteristics of vegetable proteins. Journal of the American Oil Chemists' Society , Champaign, v. 56, n. 3, p. 272-278, Mar. 1979.

HIDALGO, J. Functional properties of food proteins from a biophysical point of view: biochemical aspects of new protein food. Copenhagen : FEBS, 1977. v. 44, p. 89-98. (Symposium, A3).

HUTTON, C. W.; CAMPBELL, A. M. Functional properties of a soy concentrate and a soy isolate in simple system; nitrogen solubility index and water absorption. Journal of Food Science, Chicago, v. 42, n. 2, p. 454-456, Mar./Apr. 1977.

KAKADE, M. L.; SIMONS, N. R.; LIENER, I. E. An evaluation of natural vs. synthetic substrates for measuring the antitryptic activity of soybean samples. Cereal Chemistry, St. Paul, v. 46, n. 5, p. 518-526, Sept. 1969.

KAMER, J. H. van de; GINKEL, L. van. Rapid determination of crude fiber in cereals. Cereal Chemistry, St. Paul, v. 29, n. 4, p. 239-251, July 1952.

MATSUDOMI, N.; SASAKI, T.; KATO, A.; KOBAYASHI, $K$. Conformational changes and functional properties of acid modified soy protein. Agricultural and Biological Chemistry, Tokyo, v. 49, n. 5, p. 1251-1256, May 1985.

MATTIL, K. F. The functional requirements of proteins for foods.Journal of the American Oil Chemists' Society, Champaign, v. 48, n. 2, p. 477-484, Feb. 1971.

McWATTERS, K. H.; HOLMES, M. R. Influence of moist heat on solubility and emulsification properties of soy and peanut flours. Journal of Food Science, Chicago, v. 44, n. 3, p. 774-776, May/June 1979.

NATH, J. P.; RAO, M. S. N. Functional properties of guar proteins. Journal of Food Science, Chicago, v. 46, n. 4, p. 1255-1259, July/Aug. 1981.

NYOTU, H. G.; ALLI, I.; PAQUeTte, G. Soy supplementation of a maize based Kenyan food (ugali). Journal of Food Science, Chicago, v. 51, n. 5, p. 12041207, 1986.

PHILLIPS, R. D.; STERNBERG, M. Corn protein concentrate: functional and nutritional properties. Journal of Food Science, Chicago, v. 44, n. 4, p. 1152-1161, July/ Aug. 1979.

PIMENTEL-GOMES, F. Curso de Estatística Experimental. 10. ed. São Paulo : Nobel, 1982. 430 p.

SOETRISNO, U.; HOLMES, Z. A.; MILLER, L. T. Effect of heating times of soybean on vitamin B-6 and folacin retention, trypsin inhibitor activity, and microstructure changes. Journal of Food Science, Chicago, v. 47, n. 2, p. 530-537, Mar./Apr. 1982.

VISSER, A.; THOMAS, A. Review; soya protein products: their processing, functionality, and application aspects. Food Reviews International, New York, v. 3, n. 1/2, p. 1-32, Jan./Feb. 1987.

VOLKERT, M. A.; KLEIN, B. P. Protein dispersibility and emulsion characteristics of four soy products. Journal of Food Science, Chicago, v. 44, n. 1, p. 93-96, Jan./Feb. 1979.

WOLF, W. J. Soybean proteins: their functional, chemical and physical properties. Journal of Agricultural and Food Chemistry, Washington, v. 18, n. 6, p. 969-976, June 1970.

YASUMATSU, K.; SAWADA, K.; MORITAKA, S.; MISAKI, M.; TODA, J.; WADA, T.; ISHII, K. Whipping and emulsifying properties of soybean products. Agricultural and Biological Chemistry, Tokyo, v. 36, n. 5, p. 719-727, May 1972.

ZOIA, W. F.; WANG, S. H.; SGARBIERI, V. C. Características sensoriais e nutricionais de angus fortificados com diferentes níveis de farinha de soja desengordurada. Alimentos e Nutrição, São Paulo, v. 8, p. 49-56, 1997. 